\title{
Past, current and future of Japanese national program for earthquake prediction research
}

\author{
Naoshi Hirata \\ The Earthquake Research Institute, The University of Tokyo, 1-1-1 Yayoi, Bunkyo, Tokyo 113-0032, Japan
}

(Received December 11, 2003; Revised August 8, 2004; Accepted August 9, 2004)

\begin{abstract}
The Japanese national earthquake prediction program started in 1962 with a blue print for the scope and direction of research to follow. Substantial time and efforts were subsequently devoted to the construction of new observation networks and the study on the earthquake generation mechanisms. An important result has been the recognition of the great difficulty in identifying creditable precursors due to a diversity of earthquake generation process. In recent years, a new age of near real time observations of Earth's crustal processes by dense arrays of seismic and the GPS (Global Positioning System) stations has arrived. The results of the real time monitoring may lead to a new approach in the earthquake prediction research, i.e., the quantitative forecasting of the crustal activities. The new national program, which inherits its essential observational network from all the previous programs, emphasizes the importance of modeling as well as monitoring for a sound scientific development of earthquake prediction research. Key words: Earthquake prediction, national program, quantitative forecast, the blue print, asperity.
\end{abstract}

\section{Introduction}

National earthquake prediction research program in Japan started in 1962 with a blue print for the scope and direction of research to follow. It was carried out from 1965 to 1999 in succession of the 1 st to 7 th 5 -year program, although the first 5-year program was cut short to 4 year-period for the reason explained later. The 7 th program underwent an extensive review because of the damaging Hanshin/Awaji Earthquake, which we call the 1995 Hyogo-ken Nanbu (Kobe) earthquake, that occurred in January 1995, and for the preparation of "The new Program of Research and Observation for Earthquake Prediction" (hereinafter called the new 5-year program) which started in 1999. In March 2004, this program is completed. Internal and external evaluations of the 1st new 5-year program were made in 2002. "The 2nd new Program of Research and Observation for Earthquake Prediction" (hereinafter called the 2nd new 5-year program) is in place in 2004 .

In the new program greater importance is attached to the fundamental study beyond the traditional study of precursory phenomena. The old programs ranging from the 1 st to the 7th accumulated much knowledge regarding the basic characteristics of earthquake activities, such as sites where earthquakes occur, mechanisms of the occurrence of the earthquakes, etc. On the other hand, it has been recognized that the usual target of earthquake prediction, namely when (time), where (place), and how large (magnitude) an earthquake will occur, is in general exceedingly difficult to attain. The traditional empirical approach based on the observation of the precursor phenomena of an earthquake could not achieve the goal owing to the complexity of earthquake

Copy right (c) The Society of Geomagnetism and Earth, Planetary and Space Sciences (SGEPSS); The Seismological Society of Japan; The Volcanological Society of Japan; The Geodetic Society of Japan; The Japanese Society for Planetary Sciences; TERRAPUB. phenomena. In the new program that started in 1999, it was intended to modify the approach in a fundamental way. This paper describes an outline of the past and new national earthquake prediction research programs in Japan.

\section{The Blue Print and the First National Earth- quake Prediction Programs (1965-1998)}

The national earthquake prediction research program in Japan started with publication of a document entitled Prediction of Earthquakes-Progress to Date and Plans for Further Development (usually referred to as the blueprint; Earthquake Prediction Research Group, 1962). This became the foundation of the earthquake prediction research that led to the establishment of an observation system to collect basic data for earthquake prediction research. By the completion of the 2nd 5-year program (1969 to 1973), the basic structure of today's observation system for earthquake prediction was formed. By the end of the 3rd 5-year program, the operation of the observation system was improved and diversified. During the 3rd program specific areas of intensified research, such as the Tokai region were assigned.

In the blueprint, it was expected that a large earthquake may be predictable if we understood and were able to capture an anomalous crustal deformation as a precursor of a large earthquake or anomalous seismicity increase as foreshocks. Thus, a plan was made to monitor the crustal deformation and the seismicity in the entire Japan.

During that time, seismology was at the stage before the general acceptance of plate tectonics as well as of the fault model as the earthquake source. We did not have even a working hypothesis on the process through which an earthquake would occur in the crust. Under the circumstance, the concerned seismologists were ambitious enough to propose an empirical and experiential observation plan for earthquake prediction with a hope that it will give a better un- 
derstanding of the phenomena leading to the occurrence of a major earthquake. This proposal must be highly evaluated in view of the fact that, since that time on, the program greatly contributed to the progress of the understanding on earthquake occurrences. In the blueprint, a statement was made that we could answer the question of the earthquake predictability in 10 years after the start of the national program. However even today after 40 years, we still cannot state with sufficient certainty when an effective forewarning service will be available. We may say that the prospect was too optimistic from a viewpoint of the present knowledge of earthquakes and crustal structures. That is to say, the structure and process in the Earth's crust are much more complicated than hoped in those days, and the sites for observations are too coarsely located to detect a systematic relationship between the crustal deformation, seismicity, and large earthquakes. Furthermore, styles of anomalous phenomena (precursor phenomena) before occurrence of large earthquakes are exceedingly complicated and diversified including no precursor for some large earthquakes. Thus, it takes so much time to understand the mechanisms of the appearance of the phenomena by synthesizing the accumulated examples.

In the first 5-year program that started in 1965, it was intended that an observation system to collect various geophysical and geochemical data needed for earthquake prediction would be completed in nationwide scale within 10 years (Geodesy Council, 1964). But this was not accomplished, because during this period, the Matsushiro Earthquake Swarm (1965-1970) reached its peak in the spring of 1966 and several damaging earthquakes including the 1968 off-Tokachi Earthquake (M7.9) occurred. As a result, social demand for earthquake prediction became strong, and for a greater emphasis on practical utilization of the prediction as a target, the 1st program was terminated after 4 years and transferred to the 2 nd earthquake prediction program.

The 2nd 5-year prediction program formed the backbone of the present-day organization scheme for earthquake prediction (Geodesy Council, 1968). This began with the establishing of the Coordinate Committee for Earthquake Prediction (CCEP) in 1969 to help information exchange concerning earthquake prediction as well as to make comprehensive judgment of the information. In 1970 the Areas for Special Observation and the Areas for Intensified Observation were designated for reinforcement of the observation research. Around that time, the concept of seismic gap pointed out a high possibility of earthquakes occurring in the Tokai area and offshore of the Nemuro Peninsula. The 1973 offNemuro Peninsula earthquake (M7.4) occurred in the area expected from the gap theory (Utsu, 1972).

The 3rd 5-year program promoted new observation methods, including telemetry of seismic observation, deep borehole measurement in Tokyo Metropolitan area, cable-type ocean bottom seismographs off the cape Omaezaki, Tokai area, and bury-in type volumetric strainmeters in Tokai and southern Kanto areas, etc. (Geodesy Council, 1973). The telemetry system of the seismic networks improved the detectability of microearthquake and the accuracy of hypocenter determination, which resulted in revealing the doubleplaned structure of a deep seismic zone in the Kanto and To- hoku regions (Tsumura, 1973; Hasegwa et al., 1978). Thus, the strengthening of the earthquake prediction scheme was concentrated on the Kanto-Tokai Areas for Intensified $\mathrm{Ob}$ servation. In that period, the 1975 Haicheng, China, earthquake (M7.3) was successfully predicted using various observations including prominent foreshock activities. Issuing an order for evacuation enabled to save lives of many people. However, in the case of the 1976 Tanshang, China, earthquake (M7.8), imminent prediction was unsuccessful, resulting in a loss of many lives. In Japan, reinforcement of the program was twice motivated by the prominent seismic activities in and around the Izu Peninsula starting in 1974. In 1976 the "Tokai earthquake hypothesis" went public, which claimed that the focal area of an anticipated earthquake in Tokai area was likely to extend deep into the Suruga Bay (Ishibashi, 1981). A "Prediction Council for the Tokai Area" was established in the CCEP in 1977, and a "Large-scale Countermeasures Act" was enforced in 1978. The 1978 IzuOshima-kinkai earthquake (M7.0) occurred in the area covered by such a reinforced observation network, enabling observations of not only remarkable foreshocks but also possibly precursory anomalies in crustal strain, radon concentration in the groundwater, and the underground water level at several monitoring stations (Wakita et al., 1980).

The 4th 5-year program (1979 to 1983) emphasized the "techniques for long- and short-term prediction" (Geodesy Council, 1978). That is to say, based on the "technique of long-term prediction" to predict a "place" and "magnitude", it was emphasized to establish a "technique for short-term prediction" that seeks the "time" of occurrence of earthquakes, i.e. detection of the precursor phenomena and understanding what was really going on before the earthquake. During the program, progress was made in the measurement of the strain distribution over Japanese Island, data exchange method among microearthquake observation networks, automatic processing of the seismic data, and cable-type oceanbottom seismometers.

In 1979, with the designation of the Tokai area as an "Area under Intensified Measures against Earthquake Disaster", the Prediction Council for the Tokai Area in the CCEP was dissolved and replaced by a new "Prediction Council for Areas under Intensified Measures against Earthquake Disaster" at the Meteorological Agency, reinforcing the existing scheme for continuous monitoring in the Tokai area.

The 5th 5-year program (1984 to 1988) further improved the observation research mainly in the Areas for Intensified Observation, i.e., the Kanto-Tokai area and the Areas for Special Observation (Geodesy Council, 1983). Based on the idea of the long-term and short-term prediction, a variety of observations with improved quality and density as well as a comprehensive analysis of precursory data from various viewpoints were made in this period. It was reported that the 1983 central Japan Sea earthquake (M7.7) was associated with precursory seismicity and crustal deformation (e.g., Mogi, 1986).

In the 6th 5-year program (1989 to 1993), a basic study on inland earthquakes started because little was known about the generation mechanism of earthquakes away from plate boundaries (Geodesy Council, 1988). By the period of the 6th 5-year program, data from the high-sensitivity seis- 
mic networks developed by universities revealed large-scale three-dimensional seismic velocity structures, and then the relationship between velocity distribution and thermal structure, such as the distribution of volcanoes, was clarified (Hirahara, 1981; Hasegawa et al., 1991). Thus, the detailed seismic structure in a scale comparable to a seismogenic fault became a target of the study. The research on the 1984 Naganoken seibu (western Nagano prefecture) earthquake (M6.8) started during the 5th 5-year program and continued in the 6 th 5-year program. It was intended to understand the swarm activities and the mainshock-aftershock activity which occurred in the same area. This is the first joint observation for the inland earthquake by many institutions with modern instruments including seismic, geodetic, gravity measurements (e.g., Horiuchi et al., 1992; Hirahara et al., 1992; Kasaya et al., 2002). In the later 5-year programs, the joint observations, where many institutions jointed with their instruments and sheared the data, were conducted several times; in the area of Japanese Alps in central Honshu (e.g., Matsubara et al., 2000), Nikko area in northeastern Honshu (Horiuchi et al., 1997), Tohoku area in northeastern Honshu (e.g., Nakajima et al., 2001), Hokkaido (Katsumata et al., 2003), and southwestern Honshu, Japan. Some relationships between the heterogeneous structure of the crust, such as the seismic wave velocity distribution or electric resistivity distribution, and the distribution of microearthquakes were revealed (eg., Hirahara et al., 1992; Kasaya et al., 2001) .

Enhancement of survey technology of crustal deformation using space-based technology was achieved to increase in its efficiency: the Geographical Survey Institute, Japan, started to install the Global Positioning System (GPS) network in 1990. The GPS network enabled a continuous monitoring on crustal deformation with an accuracy of $10^{-7}$ or better at a baseline length of $100 \mathrm{~km}$.

The 7th 5-year program (1994 to 1998) started to aim at evaluation of the earthquake potential in addition to the techniques of the long-term and short-term prediction (Geodesy Council, 1993). That is to say, we tried to identify the present moment in relation to the regional earthquake cycle. For this purpose we had to understand the regional stress field, which is caused by relative plate motions to make large earthquakes along plate boundaries and/or inland areas.

To know the earthquake cycle, past histories of seismicity was investigated by paleo-seismology based on written historical records, an excavation survey, geomorphologic and geological investigations. As a result, the interval between the consecutive major earthquakes which occurred repeatedly in the individual faults has been estimated. If the time of the last major earthquake on the fault is known, the probability of the occurrence of an earthquake at present can be evaluated using a statistical model of the recurrence interval. If we can put simple physics we may improve the probability evaluation. For example, the time predictable model (Shimazaki and Nakata, 1980) would imply a longer recurrence time than average after the occurrence of an earthquake with a slip greater than the average because it takes longer time to accumulate the strain after a larger slip assuming a constant rate of strain accumulation. The research strategy based on such a physical model will be much more emphasized in the new 5-year program by which we think that earthquake occurrence forecast may be realized by understanding the whole processes in the Earth's crust leading to a large earthquake.

When the 7th 5-year program started, the October, 1994 Hokkaido Toho-oki earthquake (M8.2) and the December, 1994 Sanriku Haruka-oki earthquake (M7.6) occurred. In January 1995, the Hyogo-ken Nanbu (Kobe) earthquake (M7.3) occurred. Especially in the Hyogo-ken Nanbu (Kobe) earthquake, more than 6,000 human lives were lost and tremendous disaster struck the regions of Hanshin and Awaji. Motivated by this earthquake, the 7th 5-year program was reexamined in April 1995 and the observational research aiming to the evaluation on the earthquake occurrence potential and the survey research concerning active faults was intensified. Furthermore in June 1995, an Earthquake Disaster Countermeasures Act was enacted accompanied with the establishment of the Headquarters for Earthquake Research Promotion. During the period of the 7 th program, GPS observation networks were promoted to cover the entire Japanese Islands with a station spacing of a few tens of kilometers, which has been completed later as GEONET as discussed in the following section.

The focal area of the 1995 Hyogoken-nanbu (Kobe) earthquake was covered with a dense seismic network to clarify the aftershock activity (Hirata et al., 1996). The network consisted of two local permanent networks and one temporary network, which were connected by the Internet link. The Internet Protocol (IP) technology was used for the first time in field data acquisition and is widely used in the current data transfer method. The system was improved to use a satellite communication system for a nation-wide seismic telemetry (Urabe et al., 1998).

\section{The New Program of Research and Observation for Earthquake Prediction and the Basic Earth- quake Survey and Observation Plan}

In the new 5-year program of research and observation for earthquake prediction (referred to as the first new 5-year program; 1999 to 2003), the earthquake prediction program was reformed to put more emphasis on the fundamental study beyond the traditional study of precursory phenomena. In the mean time, the Headquarters for Earthquake Research Promotion published a document entitled the Promotion of Earthquake Research-Basic comprehensive policy for the promotion of earthquake observations, measurements, surveys and research (hereafter referred to as the Basic comprehensive policy; Headquarters for Earthquake Research Promotion, 1997). Before describing details of the first new 5year program, we shall summarize the content of the Basic comprehensive policy.

In the Basic comprehensive policy, tasks with top priorities are listed in Chapter 3 as follows.

1) Preparation of a nationwide seismic hazard map integrating results of surveys of active faults, long-term assessment of the probability of earthquake occurrence, and prediction of strong ground motion

2) Promotion of real-time transmission of earthquake information 


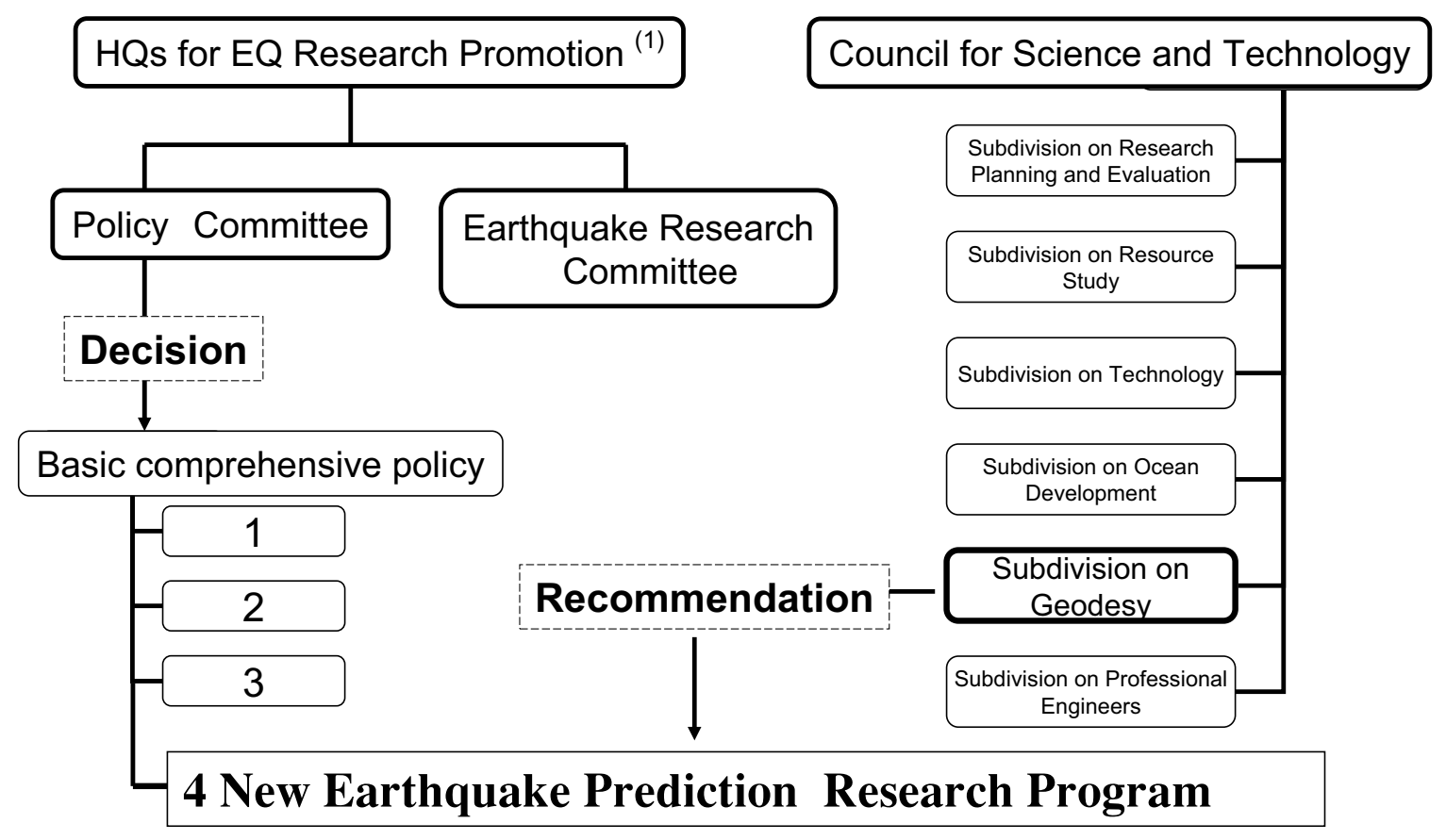

(1) Headquarters for Earthquake Research Promotion

Fig. 1. Organizational schemes for promotion of earthquake research. The headquarters for Earthquake Research Promotion determines the Basic comprehensive policy, which defines the tasks with top priorities including the earthquake prediction research program. The other three items from 1 to 3 are: 1. Preparation of a nationwide seismic hazard map integrating results of surveys of active faults, long-term assessment of the probability of earthquake occurrence, and prediction of strong ground motion, 2. Promotion of real-time transmission of earthquake information, 3. Improvement of the monitoring system in and around the area under Intensified Measures against Earthquake Disaster defined by the Large-Scale Earthquake Countermeasures Act. The earthquake prediction research program is also recommended by the subdivision on Geodesy in the Council for Science and Technology, which reflects the opinion of the scientific community in bottom-up way.

3) Improvement of the monitoring system in and around the area under Intensified Measures against Earthquake Disaster determined by the Large-Scale Earthquake Countermeasures Act

4) Promotion of research and observation for earthquake prediction

The new program of research for earthquake prediction has two positions: One is a research plan recommended by the Geodesy Council, Japan, which is now a subdivision of the Council for Science and Technology, Japan, and the other is a task with priority for earthquake disaster prevention measures (Fig. 1). The former has a function to reflect opinions of the science community in bottom-up way, which is important to make a scientifically sound plan. The latter is determined in a top-down way, which may be good for funding.

To realize the above four tasks, the Basic comprehensive policy defines the following five items as the Basic Earthquake Survey and Observation (Headquarters for Earthquake Research Promotion, 1999):

(1) Seismic observation by an array of high-sensitivity seismometers (microearthquake observation).

(2) Seismic observation by an array of broad-band seismometers.

(3) Strong ground motion observation.

(4) Observation of crustal deformation (continuous GPS observation).
(5) Active fault survey in coastal and inland regions.

The ultimate goal of the Basic Earthquake Survey and $\mathrm{Ob}$ servation is the mitigation of earthquake disaster by performing the four tasks listed above, and will be achieved through: 1. Evaluation of the possibility of the long-term earthquake occurrence. 2. Understanding and evaluation of the present state of the crustal activities. 3. Prediction of the strong ground motion and tsunami. 4. Formulation of procedure for real-time transfer of the earthquake information to public, which are the direct purposes of the above five items.

For the item (1), a station spacing of 15-20 km was recommended. This has been completed as the Hi-net by the National Research Institute for Earth Science and Disaster Prevention (e.g., Obara et al., 2000) and the seismic network by the Japan Metrological Agency. For the item (2), the recommended spacing was $100 \mathrm{~km}$ for the array of broad-band seismometers. Strong motion seismic stations, for item (3), now called K-net and KiK-net were established. For the item (4), a network of continuous GPS stations with a station spacing of 20-25 km was proposed, and resulted in GEONET operated by the Geographical Survey Institute, Japan, with 1,000 stations throughout the nation (e.g., Sagiya et al., 2000). Finally, for the item (5), 98 major faults throughout Japan were selected as the target of the trench survey and surveys would be completed by March 2005. We may say that the current earthquake observation, the crustal deformation observation by GPS, and the survey of active faults achieved so far al- 


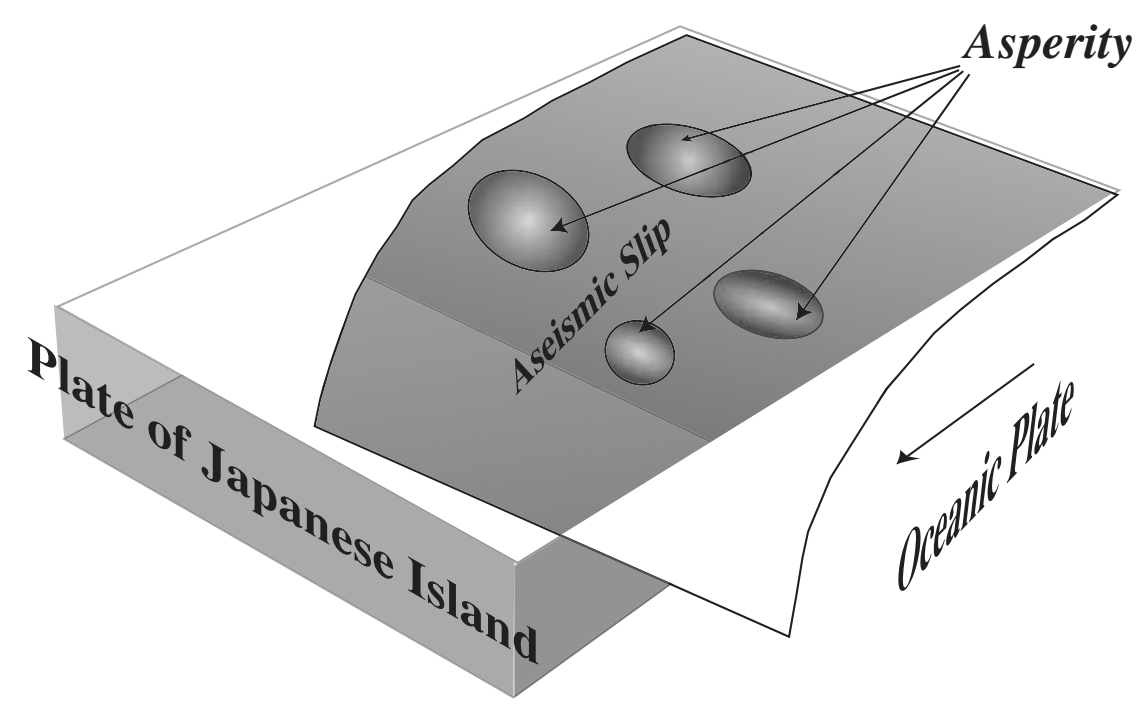

Fig. 2. Asperity model for a subduction plate boundary. The model explains the repeatability of the earthquakes by assuming a patch, called an asperity, on a plate boundary. The asperity is locked in an inter-seismic period and breaks to slip during an earthquake. Outside the asperity the plates are smoothly slipping.

ready far exceed the scope envisioned in the 1962 blueprint.

\section{The First New 5-year Program (1999 to 2003)}

Prior to the start of the first new 5-year program, the earthquake prediction research was primarily based on the empirical approach to catch creditable precursors, which must be robust. This view was too rigid to allow the inherent variability in the precursory phenomena depending on the phase of the regional earthquake cycle and also on physical and/or chemical conditions in the crust. To put the earthquake prediction research on a more flexible and scientifically sound foundation, it is essential to recognize the importance of modeling of the earthquake process in addition to monitoring. In the first new 5-year program, various modeling approaches were introduced. For example, based on the well-established fault model of earthquake, how the tectonic stress transfer due to the slip of a past earthquake affects the future occurrence of earthquakes in its vicinity was investigated (e.g., Hashimoto and Matsu'ura, 2000).

Another example is the "asperity" model, which is used to explain the recurrent earthquakes (Matsuzawa et al., 2002; Yamanaka and Kikuchi, 2004). The model explains the repeatability of the earthquakes by assuming a patch, called an asperity, on a plate boundary. The asperity is locked in an inter-seismic period and breaks to slip during an earthquake. Outside the asperity the plates are smoothly slipping. A focal area consists of either single or several asperities. If an asperity for a small size earthquake is isolated as to have no interaction among asperities, the recurrence of the earthquake may be regular because the rate of stress concentration is controlled mainly by the plate motion. If the strength of the asperity remains constant for a period of concern, say several hundreds of years, then the recurrence period is constant. This is the case of the repeating earthquakes observed off Sanriku (Matsuzawa et al., 2002). A large earthquake, which consists of more than one asperities, can be large or small depending on how many asperities are broken at once (Yamanaka and Kikuchi, 2004). However, it is not clear so far what physical condition controls its strength and life, which may indicate whether the asperity is a permanent feature on the plate boundary. The concept of asperity appeared in seismological literature back in 1980's (e.g., Lay and Kanamori, 1980) but our understanding of the state of the plate boundary makes the concept much richer than the original. That is to say, we also may understand the following findings by refining the asperity model. The continuous GPS monitoring clarifies a steady-state slip and slip-deficit on the boundary of the subducting oceanic plate and the landward plate (e.g., Sagiya et al., 2000; Nishimura et al., 2000). Importantly, a wide variety of time-constants of slip on the plate boundary is actually monitored by the continuous geodetic measurement including the GPS network and it is model by physical laws (Kato, 1999, 2003; Miyazaki et al., 2004). The slip includes a co-seismic fracture, a prominent slow inter-seismic event (Kawasaki et al., 2001; Ozawa et al., 2002), and afterseismic event (Heki et al., 1997; Hirose et al., 1999; Yagi et al., 2001). The spatial distribution of the slip and slip-deficit on the offshore plate boundary cannot be well constrained only from the land observation, even by the dense array of GPS. Thus, for better spatial resolution of the estimation of slip distribution, a new method has been developed to use repeating earthquakes on the plate boundary (Matsuzawa et al., 2002; Igarashi et al., 2003). The method incorporates spatial distribution and time-sequence of small repeating earthquakes that occur at almost identical small patches on the plate boundary, which are identified as small asperities. The asperity model assumes that only at the asperity the plates are coupled tightly, and outside the asperity the plates slip smoothly. The mode of stable and unstable sliding on the plate boundary is controlled by the constitutive law of the friction-and-fracture along the boundary (e.g., Yoshida and Kato, 2001). If this is the case, the model can be used for predicting the spatiotemporal pattern of tectonic stress due to plate-driving forces preparing for major earthquakes (Fig. 2). Modeling of aseismic episodic slip and slow after-slip of a large earthquake may also shed some light on the stress pat- 
tern and explain the diverse preparation process leading to the earthquake occurrence (Iio et al., 2003). We now further develop the concept of the asperity to establish a quantitative physical model. Another important finding is the deep nonvolcanic tremor in southwest Japan, which is also correlated to the crustal deformation detected by a tilt meter, suggesting a close relation to the subduction of the Philippine Sea plate (Obara, 2002). The observation of the deep tremor may bring us an insight about the detailed physical and chemical process undergoing on the plate boundary.

While the permanence of asperities is encouraging for modeling the tectonic stress for inter-plate earthquake, the preparation process of an intra-plate inland earthquake begins to be understood in terms of the heterogeneous structure of the crust. The 2000 Tottori Prefecture earthquake (M7.3) occurred in a region that was considered less strained according to the present day observation by the GPS array. There was also no clear active fault in the region estimated by geomorphological and geological surveys. Clearly we would first need to clarify the heterogeneity of the crust and the upper mantle with sufficient spatial resolution to understand the mechanism of concentration of stress on the fault zone.

The first new 5-year program includes also construction of simulation models for regional earthquake cycle using the finite-element method (e.g., Hyodo and Hirahara, 2003). A simultaneous study of both seismogenic structure and earthquake process promoted in the new program hopefully leads to a unified model that can explain the mechanism in which the stress generated on the plate boundary is transferred to the crust away from the plate boundary and become concentrated around a specific fault resulting in the occurrence of large earthquakes.

\section{The 2nd New 5-year Program of Research and Observation for Earthquake Prediction (2004 to 2008)}

The next 5-year program consists of the items as shown below (Council for Science and Technology, 2003).

(1) Study of the processes in the earth's crust leading to major earthquakes

The program shall promote the observational, experimental, and theoretical study to understand the process of an entire regional seismic cycle leading to major earthquakes. It is intended to incorporate all the observable phenomena including precursors in quantitative models based on the universal laws of physics and chemistry. The following 4 items will receive special attention.

\section{(1-1) Long-term large scale crustal activity}

We shall precisely determine configurations and position of the plate boundaries and relative motion of the plates constituting the Japanese island-arc and its surrounding regions in order to estimate precisely the arc-scale regional stress field and, in particular, to understand the origin of the belt, such as the Niigata-Kobe strained belt (Sagiya et al., 2000), where crustal deformation is concentrated. We shall obtain the relative velocity of the plate motion at an accuracy of approximately $1 \mathrm{~mm} /$ year in and around Japan. We shall evaluate the roles of the proposed North American, Eurasian, Okhotsk, and Amurian Plates to the earthquake preparation process.
(1.2) Preparation or Imminent processes in the crust leading to large earthquakes

The crustal activities from the preparatory stage to earthquake occurrence will be explained as a series of the processes of stress concentration from the plate-driving forces to seismogenic faults. Experimental and observational studies on detection and understanding of the irreversible physical and chemical processes immediately before earthquake occurrence shall be promoted. The regularity and fluctuation of the regional earthquake cycle shall be studied not only by a statistical model but also by a physical model. The permanence and universality of the asperity model will be important targets of the study. Since, so far, all the proposed asperities are off-shore, it is important to promote the observation in the offshore region.

\section{(1.3) Focal processes and generation of strong ground} motions

A detailed focal process of large earthquakes shall be studied by the analysis of strong ground motions to identify the areas, which may be related to the asperity(s), on the fault from which the strong seismic energy was released. Characterizations of the asperities, the direction and the speed of the rupture propagation, and the change of the stress on the fault due to earthquakes are also necessary for understanding the focal processes. The permanence of the asperity is particularly relevant to the prediction of the strong ground motion during future earthquakes. Thus, the item 1.2 is directly related to the item 1.3 . Furthermore, a detailed crustal and basement structures should be clarified for strong ground motion prediction.

(1.4) Elemental processes of earthquake generation

We need experimental and theoretical studies on rock mechanics and physical properties at high temperatures and pressures to understand the relationship between geophysical parameters observed in the field study, such as the distributions of seismic velocities and electrical resistivities in the crust, and physical properties of rocks in the crust and mantle, and a frictional and constitutive law on faults.

(2) Development of the predictive simulation models and monitoring system for the crustal activity

By comparing the observed crustal deformation data with the model simulation, we may gain better understanding in real-time crustal deformation that will help us to predict its future.

In the 1st new 5-year program, we developed a method of predictive simulation on crustal dynamics, and completed a prototype model for a specific area (e.g., Hashimoto and Matsu'ra, 2000; Hyodo and Hirahara, 2003). In the 2nd new 5-year program, we shall aim at forecast of the observable crustal activities on the basis of monitored data such as crustal deformation and seismicity in real time, by making a more realistic regional model for a specific area.

Development of integrated database for information of the crustal activity is an important item in the 2nd new 5-year program because the construction of a successful simulation model requires frequent renewals of the database for the monitored crustal activities.

(3) Development of new observational and experimental technology

In order to improve the accuracy in monitoring of the 
crustal phenomena, we need to develop new observational and experimental technologies. In particular, we need to develop a method to monitor a crustal deformation at sea bottom to practical use. The 2nd new 5-year program emphasizes the development and improvement of the various types of observation technology on the ocean bottom, the downhole measurement technology, and the technology to monitor the change in subsurface structure and state. Enhanced utilization of space technology is also emphasized.

\section{Conclusions}

The ultimate goal of the earthquake prediction research is to tell when, where, and how large an earthquake will occur. We shall approach this goal by understanding of the dynamic process in the Earth's crust through monitoring and modeling. This system will not only grasp the state of the crust leading to an earthquake with simulation of the temporal variation of the crustal activities, but also predict the strong ground motion generated by the expected earthquakes.

Thus, the 2nd new 5-year program emphasizes the importance of modeling as well as monitoring for a sound scientific development of earthquake prediction research. Of course, it inherits its essential observational network from all the previous programs. The development of a predictive simulation model was taken in as an important element of the program, because any physical understanding of a process needs a model to which universal laws of physics and chemistry can be applied. There has been an apprehension that it may be premature to adopt such a strategy now, but we feel that the time is ripe for this truly scientific approach to earthquake prediction in Japan, where an excellent monitoring system has been established through the 40-year effort.

Acknowledgments. This work is partly supported by the grant for the earthquake prediction research program funded by the Ministry of Education, Culture, Sports, Science, and Technology, and Grantin-Aid for Special Purposes (12800007). Discussion with members of the planning committee of the Coordinate Committee of the Earthquake Prediction Research in Japanese Universities is helpful. Seiya Uyeda and Keiiti Aki gave me many suggestions, which improved the manuscript very much.

\section{References}

Council for Science and Technology, On the Promotion of the Second new Program of Research and Observation for Earthquake Prediction (Recommendation), 2003 (in Japanese).

Earthquake Prediction Research Group, Prediction of EarthquakesProgress to Date and Plans for Further Development, 1962.

Geodesy Council, On the Enforcement of a National Research Program for Earthquake Prediction (Recommendation), 1964.

Geodesy Council, On the Enforcement of a Program for the Promotion of Earthquake Prediction (Recommendation), 1968.

Geodesy Council, On the Enforcement of the Third Program for the Promotion of Earthquake Prediction (Recommendation), 1973.

Geodesy Council, On the Enforcement of the Fourth National Program for the Promotion of Earthquake Prediction (Recommendation), 1978.

Geodesy Council, On the Promotion of the Fifth National Program for the Promotion of Earthquake Prediction (Recommendation), 1983.

Geodesy Council, On the Promotion of the Sixth National Program for the Promotion of Earthquake Prediction (Recommendation), 1988.

Geodesy Council, On the Promotion of the Seventh National Program for the Promotion of Earthquake Prediction (Recommendation), 1993.

Geodesy Council, On the promotion of the new Program of Research and Observation for Earthquake Prediction (Recommendation), 1998.

Hashimoto, C. and M. Matsu'ura, 3-D physical modelling of stress accumulation processes at transcurrent plate boundaries, PAGEOPH, 157, 2125-
2147, 2000.

Headquarters for Earthquake Research Promotion, Basic Earthquake Survey and Observation Plan, August 29, 1997 (in Japanese).

Headquarters for Earthquake Research Promotion, The promotion of Earthquake Research-Basic comprehensive policy for the promotion of earthquake observation, measurement, surveys and research-, April 23, 1999 (in Japanese with English translation).

Hasegawa, A., N. Umino, and A. Takagi, Double-planed structure of the deep seismic zone in the northeastern Japan arc, Tectonophysics, 47, 4358,1978 .

Hasegawa. A., D. Zhao, S. Hori, A. Yamamoto, and S. Horiuchi, Deep structure of the northeastern Japan arc and its relationship to seismic and vocanic activity, Nature, 352, 683-689, 1991.

Heki, K., S. Miyazaki, and H. Tsuji, Silent fault slip following an interplate thrust earthquake at the Japan Trench, Nature, 386, 595-598, 1997.

Hirahara, K., Three-dimensional seismic structure beneath southwest Japan: The subducting Philippine Sea plate, Tectonophysics, 79, 1-44, 1981.

Hirahara, K., N. Hirata, A. Ikami, et al., Three-dimensional P and S wave velocity structure in the focal region of the 1984 western Nagano prefecture earthquake, J. Phys. Earth, 40, 343-360, 1992.

Hirata, N., S. Ohmi, S. Sakai, K. Katsumata, S. Matsumoto, T. Takanami, A. Yamamoto, T. Nishimura, T. Iidaka, T. Urabe, M. Sekine, T. Ooida, F. Yamazaki, H. Katao, Y. Umeda, M. Nakamura, N. Seto, T. Matsushima, H. Shimizu, and Japanese University Group of the Urgent Joint Observation for the 1995 Hyogo-ken Nanbu Earthquake, Urgent Joint Observation of Aftershocks of the 1995 Hyogo-ken Nanbu Earthquake, J. Phys. Earth, 44, 317-328, 1996.

Hirose, H., K. Hirahara, F. Kimata, N. Fujii, and S. Miyazaki, A slow thrust slip event following the two 1996 Hyuganada earthquakes beneath the Bungo Channel, southwest Japan, Geophys. Res. Lett., 26, 3237-3240, 1999

Horiuchi, S., K. Ito, T. Moriya, et al., Hypocenter locations by a dense network, J. Phys. Earth, 40, 313-326, 1992.

Horiuchi, S., N. Tsumura, and A. Hasegawa, Mapping of a magma reservior beneath Nikko-Shirane volcano in northern Kanto, Japan, from travel time and seismogram shape anomalies, J. Geophys. Res., 102, 1807118090, 1997.

Hyodo, M. and K. Hirahara, Modeling of stress accumulation process on inland faults in central Japan, Earth Planets Space, 55, 667-675, 2003.

Igarashi, T., T. Matsuzawa, and A. Hasegawa, Repeating earthquakes and interplate aseismic slip in the northeastern Japan subduction zone, $J$. Geophys. Res., 108, 2249, doi:10.1029/2002JB001920, 2003.

Iio, Y., T. Matsuzawa, S. Yoshida, T. Kato, and N. Hirata, Spatial and temporal changes of aseismic slip and its role on earthquake forecasting, Zisin (J. Seismol. Soc. Jpn), 52(2), 213-229, 2003 (Japanese with English abstract).

Ishibashi, K., Specification of a soon-to-occur seismic faulting in the Tokai district, central Japan, based upon seismotectonics, in Earthquake Prediction: An International Review, edited by D. W. Simpson and P. G. Richards, Maurice Ewing Ser. vol. 4, pp. 297-332, AGU, Washington, DC, 1981.

Kasaya, T., N. Oshiman, N. Sumitomo, M. Uyeshima, Y. Iio, and D. Uehara, Resistivity structure around the hypocentral area of the 1984 Western Nagano Prefecture earthquake in the central Japan, Earth, Planets Space, 54, 107-118, 2002.

Kato, N., A possible model for large preseismic slip on a deeper extension of a seismic rupture plane, Earth Planet. Science Lett., 216, 17-25, 2003.

Kato, N. and T. Hirasawa, A model for possible crustal deformation pior to a coming large interpolate earthquake in the Tokai district, central Japan, Bull. Seismol. Soc. Am., 89, 1401-1417, 1999.

Katsumata, K., N. Wada, and M. Kasahara, Newly imaged shape of the deep seismic zone within the subducting Pacific plate beneath the Hokkaido corner, Japan-Kurile arc-arc junction, J. Geophys. Res., 108(B12), 2565, doi:10.1029/2002JB002175, 2003.

Kawasaki, I., Y. Asai, and Y. Tamura, Space-time distribution of interplate moment release including slow earthquakes and the seismo-geodetic coupling in the Sanriku-oki region along the Japan trench, Tectonophysics, 330, 267-283, 2001.

Lay, T. and H. Kanamori, Earthquake doublets in the Solomon Islands, Phys. Earth Planet. Inter., 21, 283-304, 1980.

Matsubara, M., N. Hirata, S. Sakai, and I. Kawasaki, A low velocity zone beneath the Hida Mountains derived from dense array observation and tomographic method, Earth Planets Space, 52, 143-154, 2000.

Matsuzawa, T., T. Igarashi, and A. Hasegawa, Characteristic smallearthquake sequence off Sanriku, northeastern Honshu, Japan, Geophys. Res. Lett., 29(11), 10.1029/2001GL014632, 2002. 
Miyazaki, S., P. Segall, J. Fukuda, and T. Kato, Space time distribution of afterslip following the 2003 Tokachi-oki earthquake: Implications for variations in fault zone frictional properties, Geophy. Res. Lett., 31, L06623, doi:10.1029/2003GL019410, 2004.

Mogi, K., Recent earthquake prediction research in Japan, Science, 233, 324-330, 1986.

Nakajima, J., T. Matsuzawa, A. Hasegawa, and D. Zhao, Three-dimensional structure of $\mathrm{Vp}$, Vs and $\mathrm{Vp} / \mathrm{Vs}$ beneath northeastern Japan: Implications for arc magmatism and fluids, J. Geophys. Res., 106, 21843-21857, 2001.

Nishimura, T., S. Miura, K. Tachibara, et al., Distribution of seismic coupling on the subducting plate boundary in northeastern Japan inferred from GPS observations, Tectonophysics, 323, 217-238, 2000.

Obara, K., Nonvolcanic deep tremor associated with subduction in Southwest Japan, Science, 296, 1679-1681, 2002.

Obara, K., S. Hori, K. Kasahara, Y. Okada, and S. Aoi, Hi-net: High sensitivity seismograph network in Japan, Eos Trans. AGU, 81(48), Fall Meet. Suppl., Abstract S71A-04, 2000.

Ozawa, S., M. Murakami, M. Kaidzu, T. Tada, T. Sagiya, Y. Hatanaka, H. Yarai, and T. Nishimura, Detection and monitoring of ongoing aseismic slip in the Tokai Region, Central Japan, Science, 298, 1009-1012, 2002.

Sagiya, T., S. Miyazaki, and T. Tada, Continuous GPS array and present-day crustal deformation of Japan, PAGEOPH, 157, 2303-2322, 2000.

Shimazaki, K. and T. Nakata, Time-predictable model for large earthquakes, Geophys. Res. Lett., 7, 279-282, 1980.
Tsumura, K., Microearthquake activity in the Kanto district, in Publication for the 50th Anniversary of the Great Kanto Earthquake in 1923, edited by Tsubokawa et al., Earthq. Res. Inst., pp. 67-87, 1973.

Urabe, T., N. Hirata, and K. Takano, A nation-wide seismic telemetry network in Japan using satellite communication, EOS, 79(45), F569, 1998.

Utsu, T., Large earthquake near Hokkaido and the expectancy of the occurrence of a large earthquake off-Nemuro, Rep. Coord. Comm. Earthquake Predict. 7, 7-13, 1972.

Wakita, H., Y. Nakamura, K. Notsu, M. Noguchi, and T. Asada, Radon anomaly: A possible precursor of the 1978 Izu-Oshima-kinkai earthquake, Science, 207, 882-883, 1980.

Yagi, Y., M. Kikuchi, and T. Sagiya, Co-seismic, post-seismic slip, and aftershocks associated with two large earthquakes in 1996 in Hyuganada, Japan, Earth Planets Space, 53, 793-803, 2001.

Yamanaka, Y. and M. Kikuchi, Asperity map along the subduction zone in northeastern Japan inferred from regional seismic data, J. Geophys. Res., 109, doi:101029/2003JB002683, 2004.

Yoshida, S. and A. Kato, Single and double asperity failures in a large-scale biaxial experiment, Geophys. Res. Lett., 28(3), 451-454, 10.1029/2000GL012211, 2001.

N. Hirata (e-mail: hirata@eri.u-tokyo.ac.jp) 